\title{
Genetic and Linkage Studies of New Autosomal Sex-Limited Mutant Hairless Antenna in Anopheles stephensi Liston
}

\author{
A. Dinesh Madhyastha and N. J. Shetty \\ Centre for Applied Genetics, Bangalore University, Jnana Bharathi Campus, Bengaluru 560 056, India \\ Correspondence should be addressed to N. J. Shetty; shetty_nj@yahoo.co.in
}

Received 29 August 2015; Revised 19 November 2015; Accepted 23 November 2015

Academic Editor: Fedai Erler

Copyright (C) 2016 A. D. Madhyastha and N. J. Shetty. This is an open access article distributed under the Creative Commons Attribution License, which permits unrestricted use, distribution, and reproduction in any medium, provided the original work is properly cited.

\begin{abstract}
A new morphological mutant hairless antenna (hla) was induced in the mosquito Anopheles stephensi by $\gamma$-irradiation. The expression of the mutant in the male adult revealed the antennae without the hairs. The inheritance pattern from our data demonstrates that hairless antenna is essentially sex-limited to males and is autosomal and recessive. The linkage relationships studies between the hairless antenna and greyish brown larva $(\mathrm{grb})$ mutant indicated independent assortment and are present on different chromosomes, while the linkage relationship studies between the hairless antenna and ruby eye $(r u)$ mutant revealed the suppression of hla by the ru gene in heterozygous condition. These mutants can be useful in conducting basic and applied research such as construction of linkage maps and understanding biochemical pathways and in genetic control programmes.
\end{abstract}

\section{Introduction}

Malaria continues to be a serious threat in many parts of the world including India. Conventional control method, that is, the chemical control, causes two major problems: environmental pollution and insecticide resistance. The insecticides will become less effective due to the resistance. Genetic control is an alternative method of controlling the vectors which includes techniques like sterile insect technique (SIT) and so forth and genetic characterization especially of these species and strains will continue to be an essential component of genetic control strategies aimed at disrupting the transmission of diseases [1].

Anopheles stephensi (order Diptera; family Culicidae) is an important urban malaria vector in the Indian subcontinent and accounts for about $15 \%$ of the annual malaria incidence [2]. An. stephensi has 3 pairs of chromosomes $(2 n=$ $6)$. Three pairs of chromosomes (linkage groups) based on their length and position of the centromere are designated as I (subtelocentric sex chromosomes), II (longest autosome pair), and III (shorter autosome pair) [2, 3].

Traditionally, morphological mutants have been used to construct special genetic load strains containing chromosomal translocations or inversions [4, 5]. Morphological mutants are extremely useful in understanding the biology, behaviour, and biochemical pathways involved in pigmentation and constructing linkage maps to respective chromosomes and in synthesizing new strains for control of the vector [2]. Genetic markers are necessary for expanding the linkage maps [6]. Mutants obtained by irradiation have been useful in conducting basic genetic research and also applied research. Several radiation induced morphological mutants including wing, eye, and antenna mutants have been reported in Culex pipiens [7-10].

Relatively few $\gamma$-irradiation induced morphological mutants have been discovered in Anopheles. Autosomal hairy $(h)$ and sex-linked bubble head mutants were obtained in An. albimanus [11], and frizzled $(f)$ and homochromyl (hom1) were isolated from ${ }^{60} \mathrm{Co}$-irradiated An. gambiae [12].

The present paper describes the induction and isolation of a new radiation induced morphological mutant hairless antenna ( $h l a)$, genetic basis of inheritance, and its linkage relationship with the already available autosomal mutants, that is, greyish brown larvae $(g r b)$ and ruby eye $(r u)$ in $A n$. stephensi. 


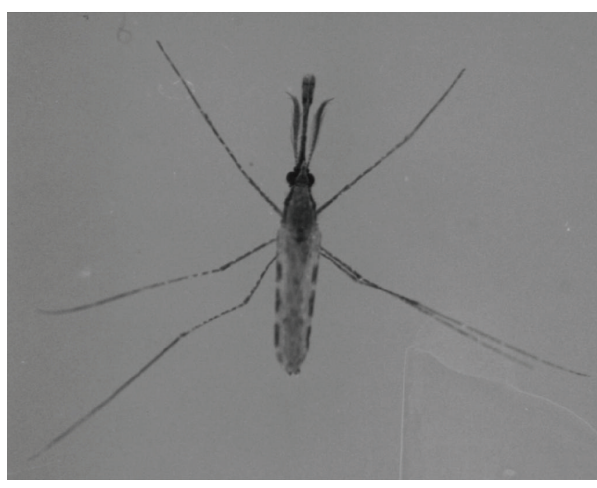

(a)

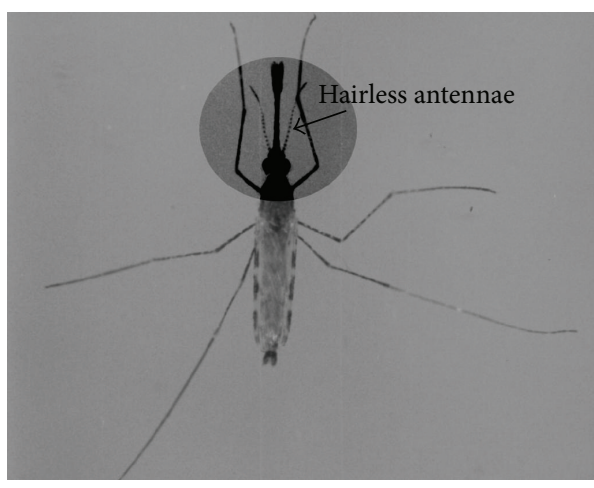

(b)

Figure 1: Male Anopheles stephensi, (a) wild type and (b) hairless antennae mutant (arrow indicating hairless antenna).

\section{Materials and Methods}

2.1. Mosquito Culture. The larvae and adults were reared in an insectary maintained at $25 \pm 1^{\circ} \mathrm{C}$ and $75 \pm 5 \%$ relative humidity according to the procedure of Shetty [13]. The adults were held in an iron cage $\left(8^{\prime \prime} \mathrm{X} 8^{\prime \prime} \mathrm{X} 8^{\prime \prime}\right)$ covered with nylon netting. The adults were fed with $10 \%$ glucose solution soaked in cotton. The gravid females were placed in a plastic cup $(2.5 \times 7.5 \mathrm{~cm})$ lined with filter paper and clean water was placed inside the cage for oviposition. The laid eggs were kept up to 72 hours for complete hatching. The hatched larvae were transferred to water in enamel tray and fed with dried yeast powder and dog biscuits as a source of food.

\subsection{Mutants}

Hairless Antennae (hla). The hairless antenna mutant was isolated from the ${ }^{60} \mathrm{Co}$-irradiated mosquitoes of the Subhash Nagar, Mysore (South India) strain. Two- to three-day-old 125 males were irradiated with 3700 rad of ${ }^{60} \mathrm{Co}$ gamma radiation (dose rate is $185 \mathrm{rad} / \mathrm{min}$ ) at the Kidwai Institute of Oncology, Bangalore. These irradiated males were immediately mass mated with virgin females of the same age. The gravid females were separated individually into plastic vials $(2.5 \times 7.5 \mathrm{~cm})$ and kept for oviposition. The lines showing less than $50 \%$ hatchability were retained and were outcrossed with wild males and females. One of the lines in the $\mathrm{F}_{2}$ generation, that is, $\mathrm{T}_{10}$, gave 130 eggs and 60 larvae with $47 \%$ hatchability. Among the 60 larvae, 30 were males and 28 were females. Out of 30 males, five were hairless antennae males. These males were outcrossed with wild type females and the resulting $\mathrm{F}_{3}$ progeny were inbred to get $\mathrm{F}_{4}$ generations. The hairless antenna males were observed in alternate generations, that is, $\mathrm{F}_{2}, \mathrm{~F}_{4}, \mathrm{~F}_{6}, \mathrm{~F}_{8}$, and so forth, and thus the mutant was maintained in the laboratory.

Contrary to the wild type male, which has bushy antennae, the mutant has hairless antennae. However, in both cases, the length and mouthparts are similar (Figure 1).

Greyish Brown (grb). The mutant greyish brown ( $g r b)$ was established in An. stephensi in our laboratory. The colour is expressed in the late 1st instar larvae and persists throughout the larval and pupal stages. The mutant colony is vigorous requiring no more care than wild type. The gene "grb" is an autosomal recessive with uniform expression and complete penetrance.

Ruby Eye (ru). The mutant ruby eye was spontaneous in origin. The ruby colour of the eye is expressed in all the developmental stages and adults. The gene " $r u$ " is monofactorial in nature and is autosomal. This is a good marker for $A n$. stephensi. The said mutant is maintained in large population cages in our laboratory [14].

2.3. Crosses. Testing the mode of inheritance of hairless antenna involved five crosses. For all crosses, 25 males and 25 females were mass mated. Cross 1 involved the crosses between the males and females of the wild type. Cross 2 involved the crosses between the hairless antenna males and wild type females. Cross 3 involved the $F_{1}$ heterozygote mated inter se. Cross 4 involved the $\mathrm{F}_{1}$ heterozygote females being backcrossed to the hairless antenna males. Cross 5 involved the crosses between the $\mathrm{F}_{1}$ heterozygote females with wild type males.

2.4. Linkage Studies. To study the linkage relationship between hairless antenna and greyish brown larva mutant, pure laboratory strains of the mutants were used. The hairless antenna males having the wild type larva body were crossed with greyish brown larva females. A total of 6 crosses were carried out to study the linkage relationship. The $\mathrm{F}_{1}$ progeny were inbred to yield $\mathrm{F}_{2}$ generation and the $\mathrm{F}_{2}$ progeny were analyzed for wild type, hairless antennae, greyish brown larva, and double mutant (hairless antenna and greyish brown larva) individuals. The same procedure was followed to study the linkage relationship between the hairless antenna and ruby eye mutant.

\section{Results and Discussion}

We have presented the genetic studies on inheritance of hairless antenna and wild type (Table 1). Cross 1 was carried 


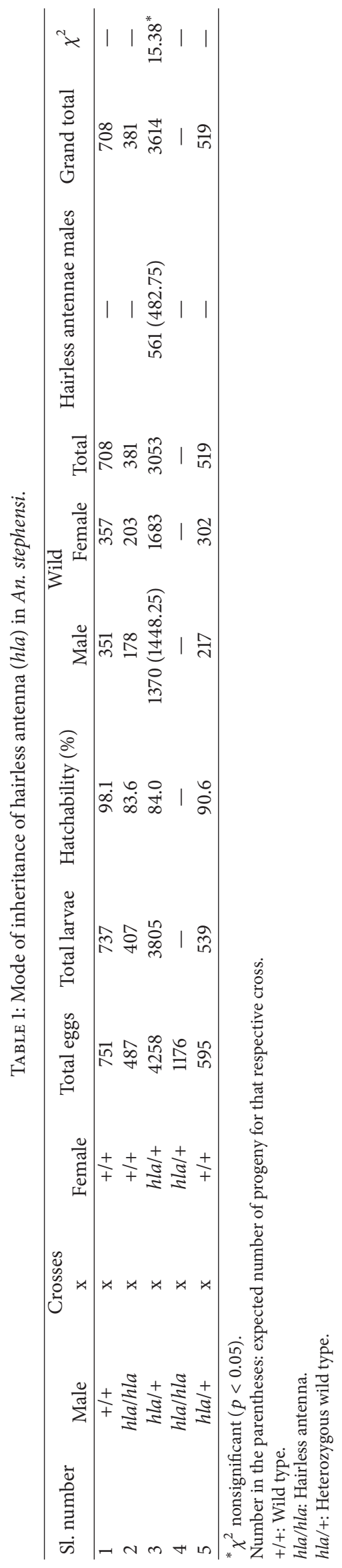


out to establish the pure-bred wild type in the laboratory. Cross 2 involved the cross between the hairless antenna and wild type female. All the males and females were normal in the $\mathrm{F}_{1}$ progeny. In cross 3 , part of the $\mathrm{F}_{1}$ progeny was inbred to get $\mathrm{F}_{2}$ progeny. The wild type male and hairless antenna mutant occurred in 3:1 ratio of the male progeny of the $F_{2}$ progeny, indicating the recessive nature of the gene hla. All the females of the $F_{2}$ progeny were of wild type, and no significant values were obtained for cross 3 . Part of the $F_{1}$ heterozygote female progeny were backcrossed to the hairless antenna (cross 4): no larva hatched out from the eggs of cross 4 . The microscopic dissection revealed no embryonic development in the eggs. In cross 5 , the $\mathrm{F}_{1}$ heterozygote male progeny was crossed to wild type females in which no hairless antenna males were observed among the $\mathrm{F}_{2}$ progeny. The heterogametic male progeny of cross 2 involving the hairless antenna and wild type female were of wild type and, therefore, the gene hla is autosomal.

Since the mutation affects only the male individuals, the gene $h l a$ is sex-limited gene. The progeny of the backcross involving the $\mathrm{F}_{1}$ heterogametic female and hairless antenna revealed only the nonembryonated eggs. The exact mechanism of the lethality of the embryo is not clearly understood. However, the lethality may be due to immobility of male gamete to fuse with an egg or incompatibility of the egg cytoplasm.

Seawright et al. [15] have reported bald antenna ( $b a)$ in An. albimanus, which was sex-limited, autosomal, and recessive. In bald antenna, the remains of the hairs of antennae were presented in the pupal moult, which is not seen in the pupal moult of hairless antenna of An. stephensi in the present study indicating that both mutants are different.

The results of the linkage studies between the hairless antenna and the greyish brown larva are presented in Table 2. Cross 1 establishes the pure breed of greyish brown larva. The $\mathrm{F}_{1}$ progeny of cross 2 involving the hairless antenna and wild type females were only wild type. The $\mathrm{F}_{1}$ progeny of cross 3 involving the hairless antenna and greyish brown larva parents were of wild type. The results of the cross 4 involving $\mathrm{F}_{1}$ progeny mated inter se showed a near $9: 3: 3: 1$ ratio of wild type, greyish brown larva, hairless antenna, and double mutant (greyish brown larva and hairless antennae) among the total male progeny in the $\mathrm{F}_{2}$ generation indicating independent assortment. The female progeny of the $\mathrm{F}_{2}$ generation showed $3: 1$ ratio of wild type and greyish brown larva. All the $\mathrm{F}_{2}$ progeny of cross 5 resembled wild type and no significant $(p<0.05)$ value was obtained for cross 4 (Table 2 ). No progeny were obtained from cross 6 . It is pertinent to mention here that the backcross carried out between the $\mathrm{F}_{1}$ heterozygote females with double mutant male (hairless antenna and greyish brown larva) did not produce any eggs indicating sterility or incompatibility. The genes grb and hla are both autosomal and the present study revealed the nonlinkage between the two genes. Therefore, these two genes are present on different linkage groups.

The results of the crosses between the hairless antenna and ruby eye are given in Table 3. Cross 1 was for establishing pure breed of ruby eye mutant. The $F_{1}$ progeny of cross 2 involving the hairless antenna and wild type females were wild type. All the $\mathrm{F}_{1}$ progeny of cross 3 involving the hairless antenna and ruby eye parents were wild type. Cross 4 involving $\mathrm{F}_{1}$ progeny being mated inter se did not reveal the normal dihybrid ratio of $9: 3: 3: 1$ of the wild type, hairless antenna, ruby eye, double mutant (hairless antenna and ruby eye) among the $\mathrm{F}_{2}$ male progeny. The actual numbers of males obtained were $52: 20: 5: 5$, respectively, for the wild type, hairless antenna, ruby eye, double mutant (hairless antenna and ruby eye). The expected numbers were $46.125: 15.375: 15.375: 5.125$. Though the wild type, hairless antenna and double mutant (hairless antenna and ruby eye) occurrence was in the expected ratio, the ruby eye expected ratio varied with observed number. Similarly, the observed female individual ratio of the wild type and ruby eye $(97: 9)$ also deviated from the expected ratio (79.5:26.5). These variations may be due to the suppressive nature of the hla gene over the ru gene. This may be in the heterozygous condition of hla gene and homozygous condition of $r u$ gene $(h l a /+r u / r u)$ individuals. In both deviations, the ruby eye individuals had 1:2 ratio of homozygous population $(+/+r u / r u)$ and heterozygous population $(h 1 a /+r u / r u)$. In the present study, observed suppression of gene activity in the progeny of $\mathrm{F}_{2}$ generation correlates with the expected $5: 10$ (15.375) and $9: 18$ (26.5) of homozygotes: heterozygotes individuals of male and female ruby eye individuals of $\mathrm{F}_{2}$ progeny, respectively. The progeny of cross 5 were wild type. No larvae hatched out from the eggs of cross 6 . For the first time such gene interaction was observed in An. stephensi and no such observations are reported so far in other mosquito species.

Genes were tentatively assigned to the linkage groups based on genetic markers in An. stephensi. A preliminary report suggested that white eye locus was on the $\mathrm{X}$ chromosome (linkage group I), brown palpi, beaked proboscis, wart, and reduced antennae on linkage group II, and 4th costal spot on linkage group III [16]. Assignment of red eye $(r)$ to linkage group I, colourless eye $(c)$ to linkage group II, and green larva $(g)$ and greenish brown larva $(g b)$ to linkage group III was tentatively made [17]. Golden-yellow $(g y)$ and black larva $(B l)$ mutants were linked with a map distance of $3.75 \pm 0.42$ and assigned to linkage group III [18]. Sequence of the genes, short palpi $(s p)$, diamond palpi $(d p)$, black larva $(B l)$, and dieldrin resistance $(D l)$ was shown to be as $s p-d p-B l$ $D l$ and they were assigned to linkage group III [19]. Spotless wings $(s l)$ and 2 nd-3rd costal spots fused (2-3f) have been mapped onto linkage group II, approximately 79.5 map units apart [6]. Three new eye colour mutants, scarlet (wsca), redspotted (prs), and pigmentless $(p)$, were found to be sexlinked (linkage group I) [20].

Larval body and eye colour mutants have been studied in our laboratory in An. stephensi. The eye colour mutants isolated include white $(w)$ [2], ruby $(r u)$ [14], and sienna $(s i)$ [21]. Larval body colour mutants include yellow $(y)$ [2], dark (da) [21], brown (b) [22], green $(g)$ [2], greyish brown ( $g r b)$ [23], grey $(g y)$ [21], greyish black $(g y b)$ [24], and green thorax (gt) [25].

Linkage studies from our laboratory showed that ruby ( $r u$ ) was nonlinked with greyish brown ( $g r b)$ [23], dark body colour $(d a)$ [2], and green thorax (gt) [25]. Sienna eye (si) 


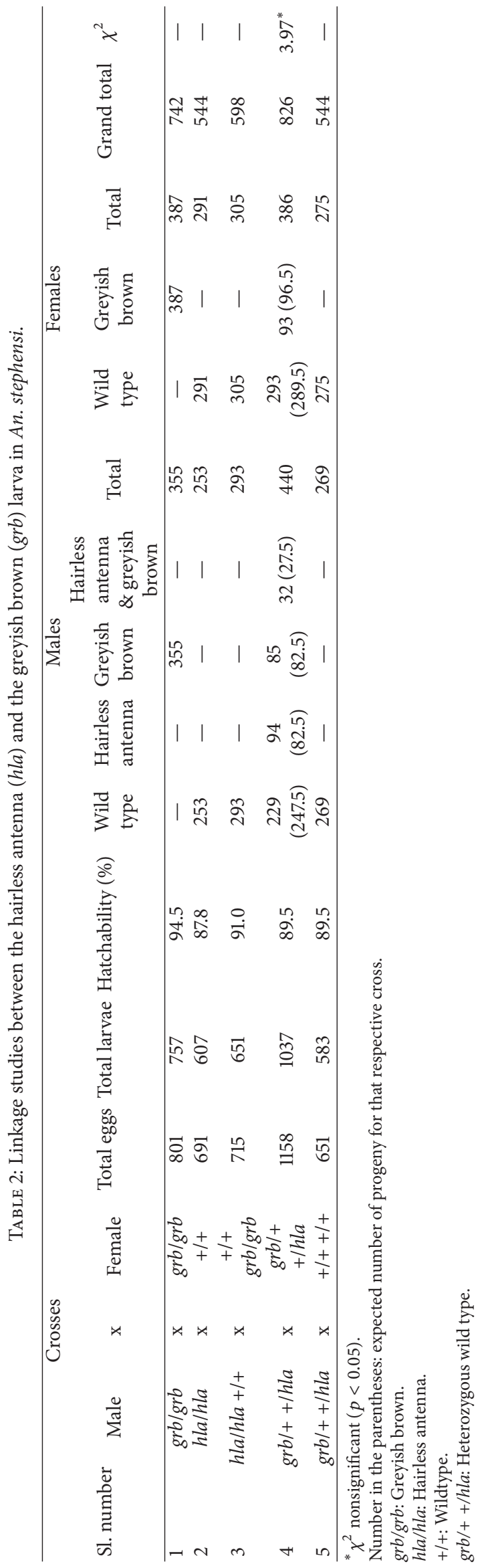




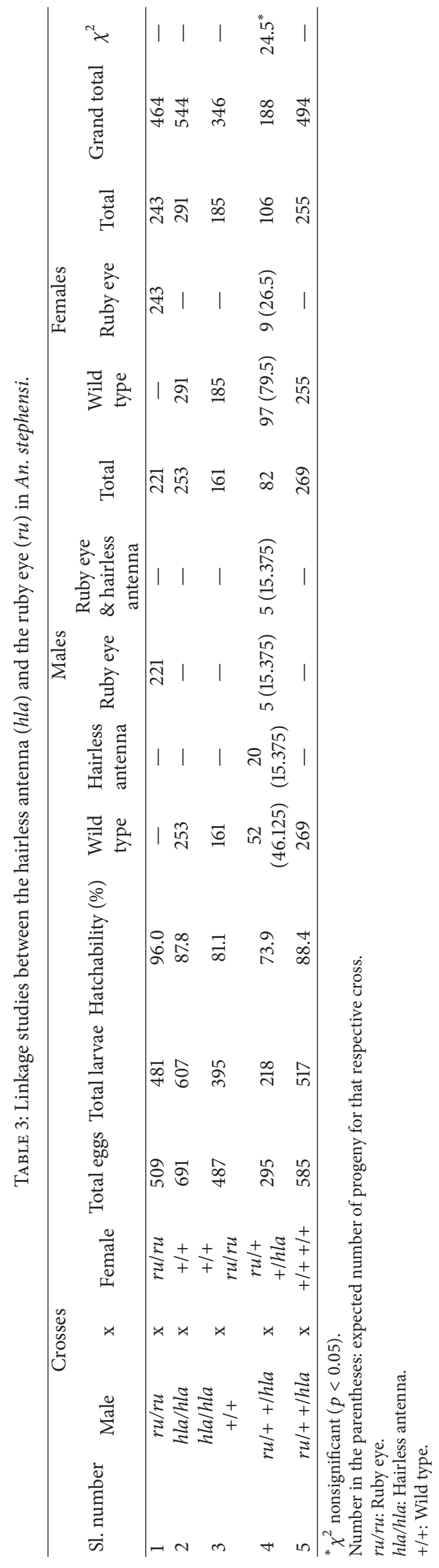


TABLE 4: A tentative linkage map of Anopheles stephensi based on morphological genetic markers.

\begin{tabular}{|c|c|c|c|}
\hline $\begin{array}{l}\text { Sex chromosome } \\
\text { (linkage group I) }\end{array}$ & $\begin{array}{l}\text { Autosome } \\
\text { (linkage group II) }\end{array}$ & $\begin{array}{l}\text { Autosome } \\
\text { (linkage group III) }\end{array}$ & Unassigned \\
\hline \multirow[t]{2}{*}{ White eye $(w)[2,16]$} & \multirow[t]{2}{*}{ Ruby eye (ru) [14] } & $\begin{array}{l}\text { Greyish brown body }(g r b) \\
\text { [23] }\end{array}$ & Yellow $(y)[2]$ \\
\hline & & Sienna eye $(s i)[21]$ & Hairless antenna ( $h l a)$ \\
\hline $\begin{array}{l}\text { Scarlet ( } w s c a) \text {, red-spotted } \\
(p r s) \text {, and pigmentless }(p) \\
\text { eyes [20] }\end{array}$ & $\begin{array}{l}\text { Brown palpi, beaked } \\
\text { proboscis, wart, and } \\
\text { reduced antennae [16] }\end{array}$ & $\begin{array}{l}\text { Dark body }(d a)[21] / \text { grey } \\
(g y)[21] / \text { greenish black } \\
(g b l)[26]\end{array}$ & \\
\hline \multirow[t]{8}{*}{ Red eye $(r)[17]$} & Colourless eye $(c)$ [17] & Green thorax $(g t)[25]$ & \\
\hline & & $\begin{array}{l}\text { Brown }(b) \text { [22]/green }(g) \\
{[21]}\end{array}$ & \\
\hline & & 4th costal spot $[16]$ & \\
\hline & & $\begin{array}{l}\text { Green larva }(g) \text { and } \\
\text { greenish brown larva }(g b) \\
{[17]}\end{array}$ & \\
\hline & & $\begin{array}{l}\text { Spotless wings }(s l) \text { and } \\
\text { 2nd-3rd costal spots fused } \\
(2-3 f)[6]\end{array}$ & \\
\hline & & $\begin{array}{l}\text { Short palpi }(s p) \text {, diamond } \\
\text { palpi }(d p) \text {, black larva }(B l) \text {, } \\
\text { and dieldrin resistance }(D l) \\
{[19]}\end{array}$ & \\
\hline & & $\begin{array}{l}\text { Golden-yellow }(g y) \text { and } \\
\text { black larva }(B l)[18]\end{array}$ & \\
\hline & & Greyish black $(g y b)$ [23] & \\
\hline
\end{tabular}

was found to be closely linked $(3.34 \pm 1.88 \mathrm{cM})$ to $\mathrm{grb}$ [21]. From the present study, the genes hla and grb were found to be nonlinked and also suppressive nature of $h l a$ gene over the $r u$ was observed.

Our allelic studies showed that brown and green larvae $(g)$ [2], grey $(g y)$ and greenish black $(g b l)$ and dark $(d a)$, and grey $(g e)$ and greenish black $(g b l)$ belong to allelic series [21, 26].

All these studies indicate that white eye is present on the sex chromosome, and green thorax, greyish brown, dark body, grey body, greenish black body, and sienna eye are present on one autosome (linkage group), while ruby eye is present on the other autosome (linkage group). Yellow, green, brown larva and hairless antennae could be on either of the autosomes (Table 4).

\section{Conclusion}

For the first time, the hairless antenna ( $h l a)$ mutant has been established in An. stephensi. The genetic studies of inheritance of hla clearly showed that it was autosomal, recessive, and sex-limited. The gene hla was expressed in males and all the females were normal. The viability of the mutant is good and can be identified very easily from the wild type without the aid of microscope. Hence, the gene hla is also considered to be an excellent marker for An. stephensi. Linkage analysis between hairless antenna and greyish brown larvae revealed that the genes hla and grb are nonlinked and could be present on different autosomes, while the data from the crosses between hla and ru revealed that the mutants segregate in nonMendelian ratio, indicating that hla prevents the expression of $r u$ in hemizygous condition.

\section{Conflict of Interests}

The authors declare that there is no conflict of interests regarding the publication of this paper.

\section{Acknowledgment}

This work was supported by financial assistance from Department of Science and Technology (DST), New Delhi, to Professor N. J. Shetty.

\section{References}

[1] E. F. Knipling, "Possibilities of insect control or eradication through the use of sexually sterile males," Journal of Economic Entomology, vol. 48, no. 4, pp. 459-462, 1955.

[2] N. J. Shetty, "The genetic control of Anopheles stephensi-a malaria mosquito," in Trends in Malaria and Vaccine Research: The Current Indian Scenario, D. Raghunath and R. Nayak, Eds., pp. 44-79, Tata Mcgraw-Hill, New Delhi, India, 2002.

[3] R. K. Sakai, F. Mahmood, K. Akhtar, C. J. Dubash, and R. H. Baker, "Induced chromosomal aberrations and linkage groupchromosome correlation in Anopheles stephensi," Journal of Heredity, vol. 74, no. 4, pp. 232-238, 1983. 
[4] D. J. Joslyn, "The state of the art of genetic control of mosquitoes," Proceedings of New Jersey Mosquito Control Association, vol. 67, pp. 64-71, 1980.

[5] R. Pal and M. J. Whitten, The Use of Genetics in Insect Control, Elsevier, North-Holland, 1974.

[6] S. D. Parvez, K. Akhtar, and R. K. Sakai, "Two new mutations and a linkage map of Anopheles stephensi," Journal of Heredity, vol. 76, no. 3, pp. 205-207, 1985.

[7] J. B. Kitzmiller, "X-ray Induced mutation in the mosquito, Culex fatigans," Experimental Parasitology, vol. 7, no. 4, pp. 439-462, 1958.

[8] H. Laven, "Strahleninduzierte Mutationen bei Culex pipiens I," Zeitschrift für Naturforschung B, vol. 10, no. 6, pp. 320-322, 1955.

[9] H. Laven, "Vererbung durch kerngene und das problem der ausserkaryotischen vererbung bei Culex pipiens: I. Kernvererbung," Zeitschrift für Induktive Abstammungs- und Vererbungslehre, vol. 88, no. 4, pp. 443-477, 1957.

[10] A. Wild, "A red eye colour mutation in Culex pipiens after Xirradiation," Nature, vol. 200, no. 4909, pp. 917-918, 1963.

[11] J. A. Seawright and M. Q. Benedict, "Recessive lethal mutations in Anopheles albimanus," Journal of the American Mosquito Control Association, vol. 1, no. 2, pp. 227-232, 1985.

[12] M. Q. Benedict, L. M. McNitt, and F. H. Collins, "Genetic traits of the mosquito Anopheles gambiae: red stripe, frizzled, and homochromyl," Journal of Heredity, vol. 94, no. 3, pp. 227-235, 2003.

[13] N. J. Shetty, "Chromosomal translocation and semi sterility in the malaria vector Anopheles fluviatilis James," Indian Journal of Malariology, vol. 20, pp. 45-48, 1983.

[14] A. D. Madhyastha and N. J. Shetty, "Ruby-eye, a new autosomal mutant in the malaria mosquito, Anopheles stephensi Liston," Indian Journal of Medical Research, vol. 115, no. 5, pp. 194-200, 2002.

[15] J. A. Seawright, M. Q. Benedict, S. Narang, and L. V. Childress, "Inheritance of bald palpi and bald antenna in Anopheles albimanus," Mosquito News, vol. 41, no. 4, pp. 660-665, 1981.

[16] M. Aslamkhan, "Sex-determination and linkage groups in Anopheles stephensi," in Proceedings of the Pakistan Science Conference, vol. 24, p. D46, Islamabad, Pakistan, 1973.

[17] S. K. Subbarao and T. Adak, "Linkage relationship between three autosomal mutants in Anopheles stephensi," Indian Journal of Malariology, vol. 18, no. 2, pp. 98-102, 1981.

[18] T. Adak, S. K. Subbarao, and V. P. Sharma, "Genetics of golden yellow larva in Anopheles stephensi," Journal of the American Mosquito Control Association, vol. 6, no. 4, pp. 672-676, 1990.

[19] K. Akhtar, R. K. Sakai, and R. H. Baker, "Linkage group III in the malaria vector, Anopheles stephensi," Journal of Heredity, vol. 73, no. 6, pp. 473-475, 1982.

[20] K. Akhtar and R. K. Sakai, "Genetic analysis of three new eye colour mutations in the mosquito, Anopheles stephensi," Annals of Tropical Medicine and Parasitology, vol. 79, no. 4, pp. 449-455, 1985.

[21] T. P. N. Hariprasad and N. J. Shetty, "Tests for allelism among colour mutants of Anopheles stephensi-Liston," The Journal of Cytology and Genetics, vol. 11, pp. 61-68, 2010.

[22] N. J. Shetty, P. Kumar, S. K. Narang, P. D. Foglesong, and D. J. Joslyn, "Brown larva: an allele of the green larva mutation in the malaria mosquito, Anopheles stephensi," Journal of Heredity, vol. 86, no. 4, pp. 309-311, 1995.

[23] A. D. Madhyastha and N. J. Shetty, "Greyish Brown-a new autosomal larval colour mutant in Anopheles stephensi liston," Journal of Cytology and Genetics, vol. 34, no. 1, pp. 79-85, 1999.
[24] N. J. Shetty, T. Zin, and M. Z. Minn, "Greyish black-a new autosomal larval colour mutant in the malaria mosquitoAnopheles stephensi Liston," Journal of Cytology and Genetics, vol. 8, no. 1, pp. 21-25, 2007.

[25] D. Sanil and N. J. Shetty, "The genetics of green thorax, a new larval colour mutant, non-linked with ruby eye locus in the malaria mosquito, Anopheles stephensi Liston," Journal of Vector Borne Diseases, vol. 46, no. 2, pp. 117-124, 2009.

[26] N. J. Shetty and C. Ghosh, "Grey larvae an allele of the greenish black larvae in the malaria mosquito Anopheles stephensi Liston," The Journal of Cytology and Genetics, vol. 6, pp. 35-40, 2005. 

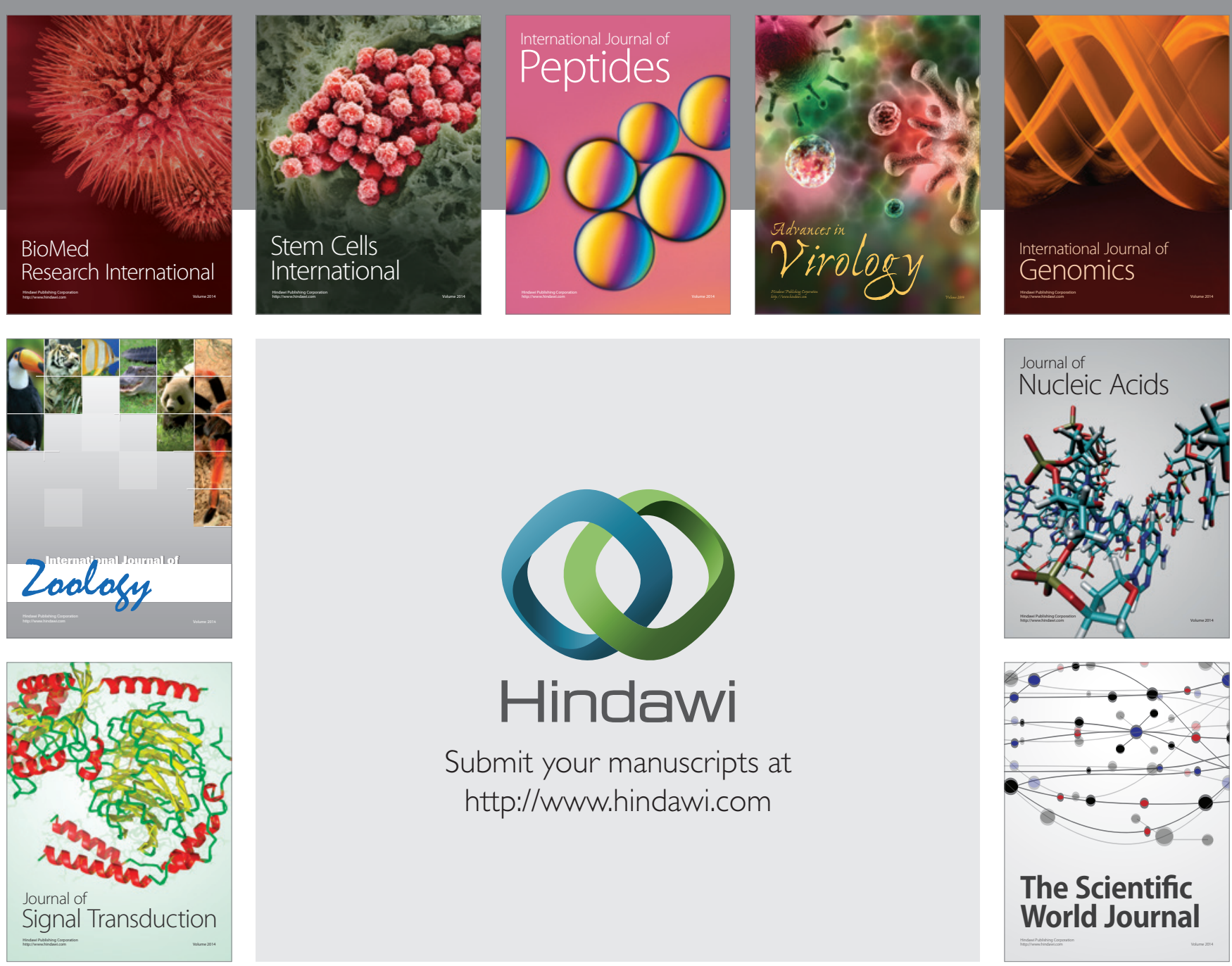

Submit your manuscripts at

http://www.hindawi.com
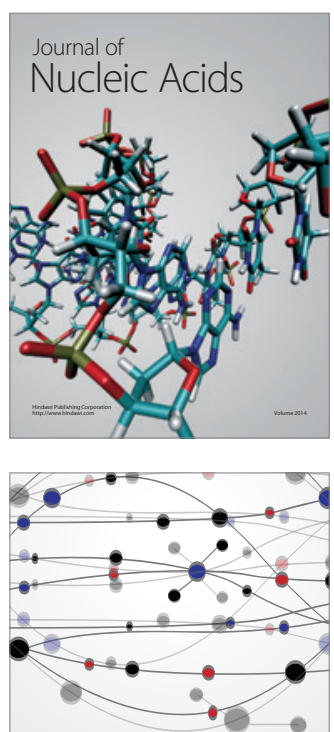

The Scientific World Journal
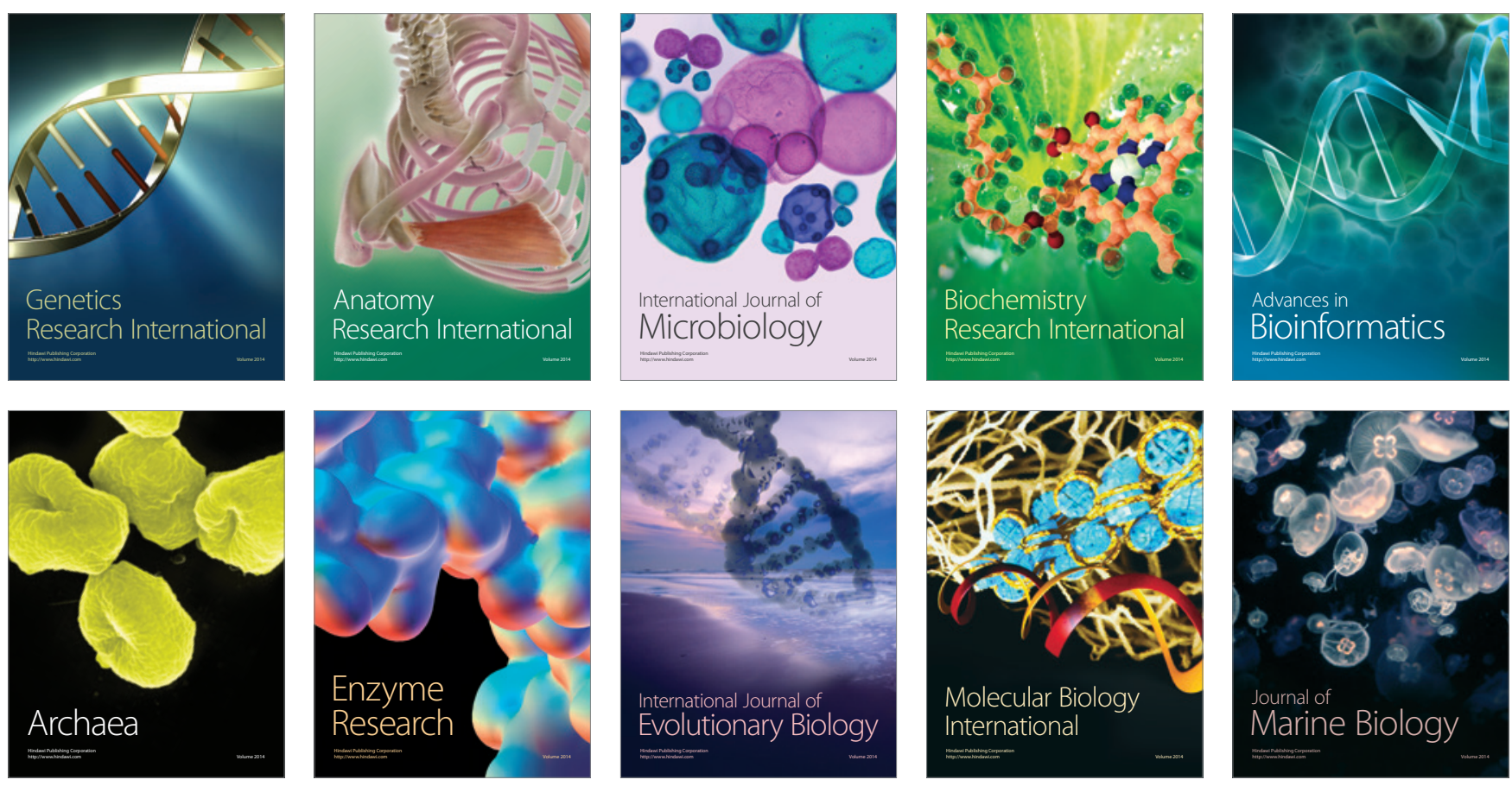